vision series-'The Ascent of Man'-which presented his personal and heroic view of science as the saviour of mankind. Bronowski died shortly after completing the programme; these lectures are the BBC's tribute to him.

Steiner is an interesting choice to lead off the memorial lectures. He has many points of contact with Bronowski; and as many differences. Both were Jewish exiles from Europe: the Nazi holocaust is writ large in both their lives, and both have shown themselves aching to find escape from it. The ultimate intellectual sanctity of science, with its references to verifiable fact, particularly in the physical sciences and mathematics, appealed deeply to both men as the antithesis of dogmatism. But whereas Bronowski searched for a release, in the fashion of The Enlightenment, for all of mankind, Steiner appears to look only towards an elite, a bright spark in the darkening eclipse of humanity.

Steiner will argue in his lecture that it is pointless to look for controls on the pursuit of science; for knowledge will out, somewhere, sometime. One day scientists will make their test-tube babies. One day there will be genetic engineering of human beings. We are powerless against the march of truth. Steiner will prove himself the hawk of science, where Bronowski was the dove. In the process he may do science a disservice. He is a great acquisitor of knowledge: 'What else is there?' he asks. Bronowski also asked for compassion, an emotion that Steiner might be suspected of dismissing as romantic.

In the 'Ascent of Man' Bronowski drew attention to a man who he said was the most intelligent he'd known: Johnny von Neumann, the originator of games theory. Von Neumann failed mankind, said Bronowski, as an intellectual elitist who believed not in the democracy but the aristocracy of the intellect. Steiner appears to fall into the same mould as von Neumann.

Steiner learned science at the University of Chicago in the late 1940s. He "scraped" a first and to his lasting regret was turned away from science by his careers advisor who said he could not cope with physics (but that was Chicago in the days of Fermi; Lee and Yang were students) and that the rest of science was "bottle-washing". Steiner, fluent in four languages, turned to journalism and ultimately to the study of language.

He would have liked to have been a biologist. His passion is mathematics and his heroes are mathematicians. The creation of melody, and of proofs (in mathematics) that the truth of a certain proposition is undecidable, are, he believes, the greatest mysteries.

Robert Walgate

\title{
ESA names European candidates for first Spacelab mission
}

THE European Space Agency (ESA) has named the four candidates from whom one will be selected to serve, along with one American scientist, as a "payload specialist" on the joint US --European Spacelab mission scheduled for the second half of 1980. The candidates were presented at a press conference on 22 December at ESA's headquarters in Paris. They are Franco Malerba, 31, an Italian electronics engineer and physicist; Ulf Merbold, 36, a West German physicist and staff member of the Max Planck Institut fur Metallforschung in Stuttgart, where he has been researching crystal lattice defects; Claude Nicollier, 33, a Swiss astronomer; and Wubbo Ockels, 31, a Dutch physicist who is doing research at the Nuclear Physics Accelerator Institute in Groningen.

With the exception of Malerba, all are married with one child. Ockels is the only non-flier in the group. Merbold is a glider pilot, Malerba holds a private pilot licence and Nicollier, after working as a professional pilot for Swiss Air, is still in the Swiss Air Force.

After three months of Spacelab familiarisation at European facilities and further evaluation in Houston, one of the four candidates will be eliminated. After next May the other three will continue training until a few months before the flight when one of them will be chosen to be the first European to travel and work in earth orbit. The other two will act as back-up specialists on the ground. On the first ESA/NASA mission lasting one week, the two scientists will be responsible for a payload of 76 experiments in the \& fields of materials science, atmospheric physics, life sciences, solar physics, astronomy, earth observation and space technology.

"We were not looking for a superman or superwoman," said Michel Bignier, Director of the Spacelab programme. $\mathrm{He}$ explained that the scientists would be working in a pressurised "shirt-sleeve" atmosphere. Nonetheless, the evaluation criteria had been particularly severe--equivalent to level II criteria used by NASA to select permanent mission specialists. "Nobody wanted to run the risk of a rejection by NASA," added $\mathrm{Mr}$ Bignier.

By last September, 53 candidates had been preselected from 2,000, including 35 women, who had responded to ESA's announcement of opportunity issued in April. One woman, AnnyChantal Levasseur-regourd of France, was among 12 finalists but failed on the last medical test.

Candidates were screened by four panels of experts covering general assessment and system engineering, scientific, psychological, and medical tests. All the candidates agreed that the psychological testing, carried out at the DFVLR Institute for Flight Medicine in Hamburg, was particularly arduous. Klaus-Martin Goeters, a member of the institute and head of the psychological panel said that tests were aimed at ensuring that those selected could cope with the stress created by the heavy Spacelab workload and the unusual environment. Drawing a typical personality profile, Dr Goeters described the successful candidate as "someone who is highly motivated, with a tendency to be an introvert, preferring small groups to a larger social context, who is unpretentious in habits and life style, thus capable of envisaging certain privations, and is highly mobile: that is a person interested in and looking for new things-with, you might even say, a taste for adventure".

Betty Werther 